\title{
Autologous Dendritic Cell-Allogeneic Melanoma Tumor Cell Lysate Vaccine
}

National Cancer Institute

\section{Source}

National Cancer Institute. Autologous Dendritic Cell-Allogeneic Melanoma Tumor Cell

Lysate Vaccine. NCI Thesaurus. Code C48376.

A cell-based vaccine composed of autologous dendritic cells (DCs) pulsed with lysates from heat-treated allogeneic melanoma tumor cells. Upon administration, this vaccine may stimulate anti-tumoral cytotoxic T-cell and antibody responses to melanoma cells bearing shared melanoma antigens such as MelanA/MART-1, gp100, MAGE3, resulting in tumor cell lysis. 